\title{
ERRATUM
}

\section{Population Pharmacokinetics of Palivizumab, a Humanized Anti- Respiratory Syncytial Virus Monoclonal Antibody, in Adults and Children}

\section{Gabriel J. Robbie, Liang Zhao, John Mondick, Genevieve Losonsky, and Lorin K. Roskos}

Medlmmune, Gaithersburg, Maryland, USA, and Metrum Research Group, Tariffville, Connecticut, USA

Volume 56, no. 9, p. 4927-4936, 2012. Page 4930, right column, line 9: The sentence should read, "Palivizumab clearance maturation was described via the following equation (1a)." See the new reference below.

Page 4931, left column, equation 10: “6,900" should be "16,900."

Page 4933: Figure 3 should appear as shown below. This corrected version now appears in the online article.

Page 4935, Figure 5 legend: The legend should read, "Group median concentration-time profiles of palivizumab at $15 \mathrm{mg} / \mathrm{kg}$ stratified by gestational age and postnatal age cohorts, 0 to 6 months (A), 7 to 12 months (B), and 13 to 24 months (C).”

Page 4936: The following reference should be added.

1a. Anderson BJ, Allegaert K, Holford NH. 2006. Population clinical pharmacology of children: modelling covariate effects. Eur. J. Pediatr. 165:819-829.

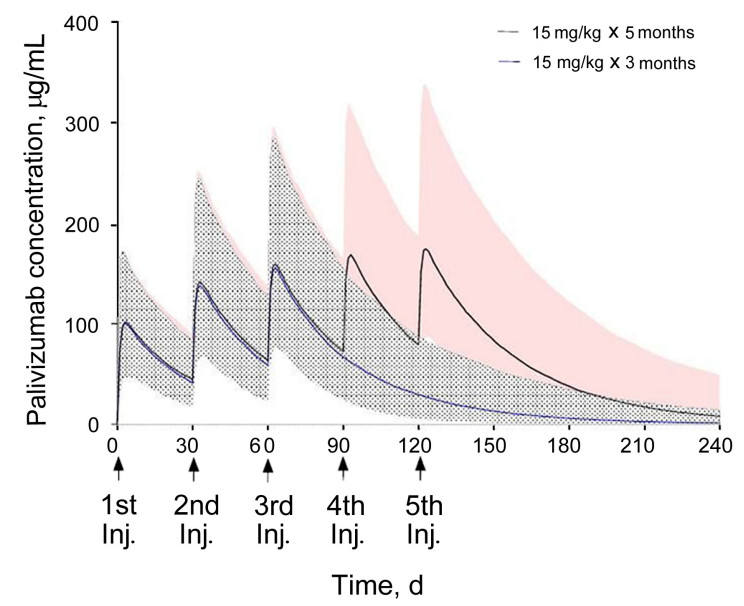

FIG 3 Simulated concentration-time profiles from the abbreviated 3 monthly $15-\mathrm{mg} / \mathrm{kg}$ doses of palivizumab compared with 5 monthly doses. Solid lines are the median predicted concentrations; shaded areas are the $95 \%$ prediction intervals. 